\title{
Healthcare and forensic medical services in police custody - to degrade or to improve?
}

\author{
Author: Jason Payne-James ${ }^{\mathrm{A}}$
}

The health needs of detainees and certain forensic processes in connection with their detention (eg determining fitness to interview, obtaining evidential samples) are functions of police custodial healthcare services (sometimes known as forensic medical services). They are essential elements of the criminal justice system. Failure of these services can result in death or harm in custody if serious health conditions are improperly assessed, and miscarriages of justice if forensic processes are improperly performed. In England, Wales and Northern Ireland a variety of healthcare professionals (HCPs) - doctors (forensic physicians, forensic medical examiners), nurses (custody nurse practitioners, forensic nurse practitioners), or paramedics (custody or forensic paramedics) - provide these services. As has been recognised for many years, ${ }^{1}$ these HCPs may have a variety of conflicting roles. It is essential that they are aware of their duties to their detainee patients and particularly aware of and sensitive to the healthcare, legal, police procedural and ethical dilemmas to which they may be exposed. All HCPs may be required to provide a written account of their findings or give evidence within court settings. Traditionally in England and Wales, the 43 police services have commissioned their own services to provide police custodial healthcare. However, the nature, delivery and costs of these services vary widely, ${ }^{2}$ impacting the quality of care. Currently, there are no basic standards for such HCPs so those with little clinical experience and no training in forensic and legal medicine may be responsible for the care of detainees.

Detainees in police custody and many complainants are a particularly vulnerable group of patients with an overrepresentation of drug and alcohol misuse and mental health diagnoses, often with chaotic lifestyles. Their substantial physical and mental needs and the significant variations in provision for police custody care have been well documented, ${ }^{3-5}$ demonstrating (compared with non-custodial populations) mixed mental health issues, drug and alcohol misuse, acute drug and alcohol intoxication, non-compliance with medication

Author: ${ }^{\mathrm{A}}$ consultant forensic physician and specialist in forensic and legal medicine, honorary consultant in emergency medicine, St George's Hospital, London, UK; honorary clinical senior lecturer, Centre for Clinical Pharmacology, William Harvey Research Institute, Barts and the London, London, UK; president, Faculty of Forensic and Legal Medicine, Royal College of Physicians, London, UK and alcohol withdrawal. Each is a significant medical risk factor alone and more so when combined. In addition, approximately $20 \%$ are children and a rising number are over 65 years in age. Thus, detainees represent a very high-risk and vulnerable patient population. This vulnerability applies also to the ability of the patients to participate fully in the criminal justice process. The Home Secretary's Commission on Appropriate Adults ${ }^{6}$ emphasised that 'any vulnerable adults do not receive the support of an appropriate adult or receive it only for part of the custody process. This undermines their welfare, inhibits the exercise of their legal rights, risks miscarriages of justice and lengthens custody times potentially increasing the risk of self-harm'. It is the HCPs who, if properly trained, are in the best position to identify such vulnerability and advise the police on these matters.

There are two other areas involving police custodial healthcare services that are particularly subject to scrutiny. First, the management of patients who have been restrained by a variety of means (eg Taser ${ }^{\circledR}$ irritant sprays) can be difficult. Restraint can be associated with death or harm, and increased Taser ${ }^{\circledR}$ usage is increasing the number of incidents seen. Secondly, HCPs may be responsible for the day-to-day care of those detained under terrorism legislation, who have enhanced level of care requirements.

The responsibility for the health of an individual does not finish as they leave the custody suite, as the recent report from the Equality and Human Rights Commission has shown. ${ }^{7}$ Often, HCPs are responsible for vulnerable patients before transfer to court, prison or immigration removal centres, or to mental health units. The thematic report by Her Majesty's Inspectorate of Prisons Court custody: urgent improvement required identified major concerns about care:

The safety and decent treatment of detainees in court custody was often neglected... little collective attention given by the various organisations to detainee care... Each court custody suite had access to health care advice from a contractor, which could also provide a paramedic if needed, but we found the service was used very little even when there was a clear need for advice. Detainees who might be unwell could therefore face long journeys without having had any medical attention... detainees who had been prescribed medication in police custody were supplied with insufficient medication to last them through a long day at court. ${ }^{8}$

This report highlighted 'the first death of a detainee in court custody for many years and the apparent homicide of a prison officer escorting defendants at Blackfriars Crown Court in July 
2015', concluding that 'there is a real risk of further serious incidents in future.

Clinicians working in this setting have long been concerned about degraded standards of healthcare, related to the outsourcing of services to a variety of providers who were not obliged to recruit HCPs with any relevant minimal skill set. The Faculty of Forensic and Legal Medicine (FFLM) of the Royal College of Physicians, and others, have raised concerns about the potential for increased harm and deaths in police custody. In July 2015, the Home Secretary announced that there was to be an inquiry into deaths in police custody, as numbers had risen to their highest level for 5 years. ${ }^{9}$ The FFLM wrote advising that such an inquiry must extend beyond deaths in custody to include other serious incidents and healthcare provision, a concern accepted by the Home Secretary. Dame Elish Angiolini, was appointed Chair of the Review - which is due to report its findings early in 2017.

The safety and wellbeing of detainees is paramount and the clinicians practising within this setting have proposed the transfer of healthcare and forensic medical services for police custody to the NHS for many years. Forerunners of the FFLM, the Association of Police Surgeons and the Association of Forensic Physicians, proposed this step decades before the FFLM was created. The aim of such a transfer was to improve the standards of care to detainees in police custody by ensuring that appropriately trained HCPs are responsible for the medical care of detainees in police custody, with defined minimum standards of training, competencies and qualifications being required before being able to work autonomously in the police setting. In 2009, the Home Secretary confirmed that guidance as to the level of professional and clinical qualification required for doctors or nurses would be issued by the FFLM.$^{10}$ Subsequently, the FFLM and its clinical partners (the United Kingdom Association of Forensic Nurses \& Paramedics and the College of Paramedics) issued a consensus statement on the minimum qualifications that should be required. ${ }^{11}$ Substantial work over a 3 -year period was undertaken by the Home Office and the Department of Health (with NHS England) in collaboration with the clinical partners to drive the aim of all services being commissioned by the NHS from 1 April 2016. This strategic aim appeared to be moving towards fulfillment. This transfer was strongly supported by clinical partners as it was believed that it would result in appropriate governance, standards and services being provided instead of the current postcode lottery of variable service provision to police services in England and Wales, with its concomitant risks to patient safety. However, the clinical partners did make very strong suggestions that the NHS specification for such services incorporate whatever recommendations would be made by the Angiolini review, and advised a delay until after its publication and due consideration of the findings. Then on 17 December 2015 the Home Secretary announced, to all interested parties' shock, that the entire proposed transfer was cancelled. Despite intensive efforts to find out why, no clear reason for this bizarre and perverse decision has yet been given.

The care of vulnerable detainees in police custody is therefore back to square one; with no enforceable minimum national standards, no governance and no cohesive plan apparent. Standards are crucial to ensure that HCPs have the appropriate skills to identify and understand the specialist forensic medical needs of the police service and the criminal justice system. The transfer of healthcare was intended to achieve equity of care to that available in the community (as in other secure settings), and to increase opportunities for appropriate diversion for treatment for people whose offending is directly related to mental health, drug or alcohol issues.

We have to hope that the Angiolini review will recommend that HCPs be required to have a minimal standard of training, competencies and qualifications as recommended by the clinical partners, and that the Home Secretary will accept all recommendations and re-start the NHS transfer process with appropriate funding. It is also to be hoped that politicians of all hues might support such an approach although track records of most suggest that care of the vulnerable in police custody is way down on their list of priorities. The FFLM and its clinical partners will continue to lobby all interested parties intensively to improve standards of healthcare to the levels that national and international conventions require, and to ensure that forensic medical services do not further degrade so that we can have confidence that detainees are safe and the risks of deaths and harm in custody and miscarriages of justice are minimised.

\section{Conflicts of interest}

The author has no conflicts of interest to declare.

\section{References}

1 Three-faced practice: doctors and police custody. Lancet 1993;341:1245-7.

2 Payne-James JJ, Anderson WR, Green PG, Johnston A. Provision of forensic medical services to police custody suites in England and Wales: current practice. J Forensic Leg Med 2009;16:189-95.

3 Payne-James JJ, Green PG, Green N et al. Healthcare issues of detainees in police custody in London, UK. J Forensic Leg Med 2010;17:11-7.

4 McKinnon I, Grubin D. Health screening in police custody. J Forensic Leg Med 2010;17:209-12.

5 Rekrut-Lapa T, Lapa A. Health needs of detainees in police custody in England and Wales. Literature review. J Forensic Leg Med 2014;27:69-75.

6 Bath C, Bhardwa B, Jacobson J, May T, Webster R. There to help: ensuring provision of appropriate adults for mentally vulnerable adults detained or interviewed by police. Ashford: National Appropriate Adult Network, 2015.

7 Phillips J, Gelsthorpe L, Padfield N, Buckingham S. Non-natural deaths following prison and police custody. Research report 106. London: Equality \& Human Rights Commission, 2016.

8 Her Majesty's Inspectorate of Prisons. Court custody: urgent improvement required. London: HM Inspectorate of Prisons, 2015.

9 Independent Police Complaints Commission. Death during or following police contact: statistics for England and Wales 2013/14. London: IPCC, 2014.

10 Smith J. Forensic science. Daily Hansard - Written Answers 2009;489:1164W. www.publications.parliament.uk/pa/cm200809/ cmhansrd/cm090318/text/90318w0006.htm\#09031889000078 [Accessed 12 October 2016].

11 Faculty of Forensic \& Legal Medicine. Press release: Doctors, nurses and paramedics working in police custody call for standards to protect patients and avoid miscarriages of justice. London: FFLM, 2015. www. fflm.ac.uk/2015/10/spress-release-doctors-nurses-and-paramedicsworking-in-police-custody-call-for-standards-to-protect-patientsand-avoid-miscarriages-of-justice/ [Accessed 12 October 2016].

Address for correspondence: Dr Jason Payne-James, The Office, Southminster, Essex CMO 7DT, UK.

Email: jasonpaynejames@aol.com 